\title{
SUCESSO NA CARREIRA NA PERSPECTIVA DE UNIVERSITÁRIOS
}

\section{SUCCESS IN THE CAREER UNDER PERSPECTIVE OF UNIVERSITY STUDENTS}

\author{
Fabiana Pinto de Almeida Bizarria ${ }^{1}$ \\ Mônica Mota Tassigny² \\ Antônio Jackson Alcântara Frota ${ }^{3}$ \\ Heber José de Moura ${ }^{4}$ \\ Alex Bizarria Bezerra ${ }^{5}$
}

\begin{abstract}
Resumo
O presente estudo objetiva analisar a percepção de estudantes universitários acerca de seu sucesso na carreira por meio da Escala de Percepção de Sucesso na Carreira (EPSC) com 10 itens, em sua versão reduzida, distribuídos em duas dimensões (subjetiva e objetiva). Realizou-se um survey descritivo,com 105universitários de uma Instituição de Ensino Superior, situada em Fortaleza-CE. Foram utilizados procedimentos de Análise Fatorial Exploratória e confirmatória e Análise de Cluster para interpretação e análise dos dados, e análise descritiva dos dados. Identificou-se uma estrutura quadridimensional, formada pelas dimensões, em ordem decrescente de importância, Impacto da Renda, Complexidade do Trabalho, Bem-estar no Trabalho e Perspectiva de futuro. A pesquisa contribui com a discussão sobre o estudo do sucesso na carreira numa perspectiva da formação acadêmica. A ampliação da pesquisa, como forma de driblar suas limitações poderia caminhar no sentido de investigações com uma amostra mais abrangente e diversificada.
\end{abstract}

Palavras-chave: Sucesso na Carreira. Universitário. Discentes.

\begin{abstract}
This study aims to analyze the perception of college students about their career success through the success of Perception Scale Career (EPSC) with 10 items in its reduced version, distributed in two dimensions (subjective and objective). We conducted a descriptive survey, 105 students of a higher education institution, located in Fortaleza-CE. Analysis procedures were used Exploratory and confirmatory factorial and cluster analysis for interpretation and data analysis, and descriptive data analysis. Identified a four-dimensional structure formed by the dimensions, in descending order of importance, Impact of Income, Labor Complexity, Wellbeing at Work and future perspective. The research contributes to the discussion on the study of career success from the perspective of academic training. The expansion of research as a way to circumvent its limitations could move towards research with a broader and more diverse sample.
\end{abstract}

Key-words: Successful career. University. Students.

\footnotetext{
${ }^{1}$ Universidade de Fortaleza. Doutorado em Administração (em andamento) na Universidade de Fortaleza (Unifor). Mestrado Acadêmico em Administração (Unifor) E-mail: bianapsq@ hotmail.com

${ }^{2}$ Universidade de Fortaleza. Doutorado em Educação pela Universidade Federal do Ceará (2002) e doutorado na Ecole des Hautes Etudes en Sciences Sociales (Paris). Professora titular do Programa de Pós Graduação em Administração UNIFOR (PPGD) e Professora colaboradora do Programa de Pós-Graduação em Direito (PPGD/UNIFOR).E-mail: bianapsq@hotmail.com

${ }^{3}$ Universidade de Fortaleza. Mestre e doutorando em Administração de Empresas - UNIFOR. E-mail: bianapsq@hotmail.com

${ }^{4}$ Pós-Doutorado em Risco Operacional realizado - UFPe. Doutor em Administração pela FGV/SP. E-mail: bianapsq@hotmail.com

${ }^{5}$ MBA Executivo em Negócios Financeiros e atualmente é Mestrando em Administração - Universidade Estadual do CearáE-mail: rosele@uems.br
}

Artigo recebido em: 01 de setembro de 2017. Artigo aceito em 18 de maio de 2018. 


\section{Introdução}

O trabalho é inerente à experiência do ser humano com o mundo, desde os primórdios das civilizações. No contexto do trabalho contemporâneo, constatam-se níveis crescentes de responsabilidades em atividades cada vez mais complexas e em constante mudança, considerando a ampliação da competitividade, variabilidade e atribuição de múltiplas tarefas aos cargos, emergências de crises financeiras, reflexo das transformações do mundo laboral que reforçam o aumento da incerteza, da percepção de risco, da fragilização e ruptura dos vínculos tradicionais de trabalho (BORGES; MOURÃO, 2013; ROCHA et al., 2013; COSTA, 2014).

As mudanças nas formas de conceber carreira por indivíduos e organizações, materializam transformações contextuais na profissionalização, no vínculo de emprego, nas identidades profissionais, na arquitetura das carreiras e no surgimento de novos arranjos profissionais, denominados de trabalhos não convencionais. Com a emergência de novas significações para carreira, muda-se o discurso da situação em que a organização é centro, que prenominou o século $\mathrm{XX}$, para a ideia de trajetória, condicionada por experiências acumuladas em seu percurso (DUARTE; SILVA, 2013).

Nesse sentido, as carreiras,na atualidade, não são identificadas como sistemas previsíveis e lineares, com suporte em estruturas de cargos que definem caminhos a priori, mas se exige um novo posicionamento em relação à vida laboral, uma postura mais ativa do sujeito na construção do projeto de vida. Carreira se apresenta, portanto, como uma forma de mediação entre sujeito, trabalho e sociedade(MAGALHÃES, BENDASSOLLI, 2013).

Questões elaboradas por Chanlat (1996) ainda repercutem na discussão atual sobre carreira e demonstram como o tema dialoga com contextos mais amplos. Como falar de carreira, quando o mercado de trabalho tem demandado, cada vez menos, empregos estáveis e bem remunerados? Quando a forma de gestão está dominada por preocupações essencialmente financeiras? Quando se observa um declínio da ética do trabalho? Quando os sistemas de formação estão em crise? Quando o horizonte profissional é cada vez mais curto?

Essas questões não geram respostas imediatas, nem fechadas. Neste estudo, busca-se atenção especial para a perspectiva da formação na constituição de carreira, e de como esta é percebida por estudantes universitários com a premissa de sucesso. Tal 
preocupação também se justifica pela expansão do ensino superior brasileiro que se alinha a uma maior perspectiva de desenvolvimento socioeconômico, pela maior capacidade de qualificação profissional para atender às demandas do mercado (CABRAL et al., 2011). Como indicativo desse aumento, fornecidos pelo Censo de 2010 sobre a educação superior, informam que em 2010, o total de 6.379.299 matrículas em cursos de graduação é mais do que o dobro das registradas em 2001.

Com o aumento de universitários, este estudo prioriza carreira. Estudos apontam a necessidade de maior investigação sobre o tema, como o estudo de Coelho (2000), citado por Lemos et al. (2007, p. 212), que investigou a percepção de formandos sobre o mercado de trabalho e contatou que "há uma discrepância entre a percepção quanto às exigências do mercado e as ações efetivadas para enfrentar esses desafios". Outros estudos são apresentados por Lemos et al. (2007):uma pesquisa realizada por Teixeira e Gomes (2004) indica que formandos são otimistas em relação à inserção no mercado, mas percebem que as oportunidades são limitadas.Outro estudo feito por Gondim (2002) aponta que o formando possui conhecimento sobre a profissão escolhida, em geral, por meio de informações transmitidas pelos meios de comunicação, entretanto, mas não consegue identificar de que maneira mais adequada seu perfil de busca profissional na sua área de atuação seria ajustado segundo suas competências, bem como, suas habilidades (LEMOS, et al., 2007).

Diante desse contexto, pretende-se responder ao seguinte questionamento: quais os fatores determinantes da percepção de sucesso na carreira de universitários já inseridos no mercado de trabalho? Com isso, tem-se como objetivo geral dimensionar a percepção de sucesso na carreira com suporte na Escala de Percepção de Sucesso na Carreira (EPSC) (DUTRA et al., 2009; SIQUEIRA et al., 2014).

\section{FORMAÇÃO UNIVERSITÁRIA E DILEMAS DA VIDA UNIVERSITÁRIA}

Constata-se uma relação estreita entre campos profissionais e a sociedade em que esses se inserem. É bem verdade que a formação de um profissional exige um constante contato com o acervo científico e tecnológico, provendo o formando de instrumental para o aprendizado, bem como, de experiências para responder às interpelações impostas pela sociedade em geral e, dessa forma, dando-lhe condições para corresponder a problemas concretos pelos quais será possível apresentar sua capacitação motivacional para determinada área profissional (BASTOS; YAMAMOTO; 
RODRIGUES, 2013).

Nesse sentido, a formação universitária representa o espaço instituído pela sociedade para promover um repertório de conhecimento e habilidades que sustentam os campos profissionais e habilitam os sujeitos a exercerem profissões. Além do conhecimento científico, se esperam, de um profissional com formação universitária, habilidades e conhecimentos relacionados à atividade laboral e, também, aquelas relacionadas ao contexto que favoreçam o desempenho do indivíduo, dando maiores chances de avanço na carreira (BENDASSOLLI; MALVEZZI, 2013).

A ideia de carreira consolida uma forma pessoal de construção de significados na experiência de trabalho, representando um meio social de organizar a vida laboral. A carreira também envolve "comportamentos, expectativas, necessidades, cognições e sentimentos de uma pessoa em um processo de auto desenvolvimento orientado por objetivos de vida e trabalho, ambos mediados pelo mercado" (MAGALHÃES, BENDASSOLLI, 2013, p. 440).

No momento de conclusão de um curso universitário, os estudantes expressam seus anseios de diferentes formas. Alguns enfatizam os desafios e as barreiras com uma postura mais passiva, outros exploram possibilidades profissionais com referência nas experiências e oportunidades da vivência acadêmica, aumentando o repertório de competências que favorecem o ingresso no mercado de trabalho (SILVA;TEIXEIRA, 2013). Dessa forma, a variabilidade de significados que os estudantes atribuem à carreira segue condições sócio-históricas, delimitadas por uma dimensão concreta, representada pelas condições materiais e/ou ambientais, uma dimensão gerencial, expressa pelo planejamento, direção e escolhas; uma dimensão socioeconômica, que abrange a interação entre a atividade laboral e as estruturas social, econômica e política, a dimensão ideológica, que compreende o discurso elaborado sobre o trabalho e uma dimensão simbólica, que corresponde aos aspectos subjetivos da relação dos sujeitos com o mundo do trabalho (BORGES; YAMAMOTO, 2004).

A realidade de mercado em cada profissão demonstra que um certificadodiploma não revela mais garantia de emprego, uma vez que, as vagas e oportunidades diminuíram com o advento do desenvolvimento tecnológico, exigindo dinâmica, flexibilidade e dedicação motivacional para que o indivíduo que concluiu o curso universitário alcance a vaga profissional almejada.Por vezes, a percepção de carreira se torna marcada pelas incertezas e questionamentos dos formandos e recém-formados 
devido a dois fatores que influenciam nessa perspectiva: o primeiro consiste nas incertezas de alocação no mercado e o segundo decorre da deficiência de conhecimento adquirido em todo o tempo gradual do curso.

A percepção de sucesso na carreira se evidencia em dois âmbitos de observação: o primeiro foco se dá na pessoa que assume um conjunto de características formando um perfil que delineia uma carreira profissional, e o segundo foco é a organização que assume o compromisso de facilitar a responsabilidade de gerir a própria competitividade profissional.

É bem verdade que nas relações de trabalho surgem dificuldades em analisar a percepção de sucesso na carreira de forma individual, uma vez que, ao questionar a percepção se notam elementos basilares nessa análise, como: expectativas, frustrações e fatores que o próprio ambiente organizacional proporciona, o que diferencia a percepção de cada indivíduo, questionado em sua percepção de sucesso profissional (COSTA; VIEIRA, 2014).

$\mathrm{O}$ enfoque dado à percepção de carreira vem se adequando às muitas incertezas que o contexto socioeconômico gera no mercado de trabalho.Essas incertezas impactam proporcionalmente uma linearidade de sucesso na carreira profissional, por isso mesmo, nota-se uma busca constante por independência na condução da gestão da própria carreira, conduzindo-a com dinamismo e tomando para si as oportunidades que surgem diante do perfil almejado (LIMA; ARRAES et al., 2014).

As perspectivas, a interpretação e a identificação de sucesso na carreira definem, por vezes, a trajetória que o indivíduo traça como sua definição de carreira de sucesso, de modo que a própria pessoa obtenha uma vida profissional mais realizada, motivando as organizações a se debruçar nessa questão para que estas desenvolvam estratégias organizacionais de retenção dos bons profissionais (LIMA; ARRAES et al., 2014).

O próprio percurso universitário constitui-se de forma relevante para o desenvolvimento de carreira. Essa trajetória é construída de forma individualizada por meio do interesse pessoal, da motivação, da maturidade e das decisões sobre carreira. Se os projetos não forem fruto de uma percepção positiva do mercado e das oportunidades de inserção, isso pode repercutir em projetos de carreira vagos e incompatíveis com o perfil do aluno e com as leituras dele sobre a profissão escolhida (SILVA, 2010; SILVA; TEIXEIRA, 2013).

A qualidade da transição universidade-trabalho revela-se como fruto de um 
planejamento prévio da carreira, em que o universitário se apropria das várias experiências acadêmicas e das opções diante da necessidade de escolha, influenciando o seu desenvolvimento pessoal e profissional.O formando universitário, por vezes, é desafiado pela sociedade a enfrentar a complexidade de vários processos de seleção, colocando em teste os sentimentos que revelam a competência e a habilidade sempre desafiadas pela projeção, e busca da realização dos projetos de carreira (MAGALHÃES; TEIXEIRA, 2013).

A ansiedade, por exemplo, tem um papel importante nas futuras decisões, principalmente quando o mercado de trabalho não se mostra favorável à escolha realizada. Outras variáveis influenciam as decisões diante do futuro profissional, como: clareza de autoconceito, expectativas de autoeficácia, comportamento exploratório, percepção de barreiras e apoio e a percepção de possibilidades pessoais diante da carreira(PERRONE; VICKERS, 2003; TEIXEIRA; GOMES, 2005; KOEN; KHLEHE; VAN VIANEN, 2012; SILVA; TEIXEIRA, 2013).

Diante dos novos perfis profissionais, os universitários se deparam com a necessidade contínua deformação para uma melhor inserção no mercado de trabalho, por meio de uma aprendizagem em tempo mais curto, adequada à sua condição humana, ou solicitada a alterar sua identidade, sem que isso faça parte de seus planos de vida (PERRONE; VICKERS, 2003; BORGES; YAMAMOTO, 2004; SILVA; TEIXEIRA, 2013). Nesse sentido, quando o foco da transição é se inserir no mercado de trabalho de forma prioritária, sem uma análise mais acurada de outras variáveis inerentes à escolha profissional, os alunos ficam mais sujeitos a uma maior possibilidade de frustração diante do projeto pós-formatura (KOEN; KHLEHE; VAN VIANEN, 2012).

\subsection{Concepções sobre Carreira e Sucesso na Carreira}

No contexto atual do mercado de trabalho, espera-se dos sujeitos maior envolvimento profissional de forma que se tenha um projeto de vida que priorize o planejamento pessoal em consonância com diversos papéis assumidos ao longo da vida laboral e que sirva de referência para escolhas em relação à carreira (ROCHA et al., 2013).

Atribui-se que a concepção de carreira, estágios e transições são consequência de necessidades, motivos, aspirações, expectativas e imposições experiência das pela vida em sociedade (COSTA, 2010, 2014). Além disso, uma carreira inclui atividades desempenhadas ao longo da vida, abrangendo trabalhos formais, informais $\mathrm{e}$ 
voluntários, estudos e outras experiências adquiridas pelo sujeito,que favorecem o desenvolvimento de competências profissionais para lidar com situações de vidatrabalho, capacitando-o para níveis crescentes de responsabilidades em atividades cada vez mais complexas e em constante mudança (COSTA, 2014,MOTTA, 2006, DUTRA et al., 2009).

Por sua vez, não se pode afirmar que carreira é produto de uma posição individual, apenas, visto que na sua estrutura há um “inter jogo entre os papéis sociais, ocupacionais ou profissionais de uma pessoa e seu próprio autoconceito, valores, experiências passadas, recursos e planejamento para o futuro" (MAGALHÃES, BENDASSOLLI, 2013, p. 440).

Estudos sobre carreira aparecem de forma mais estruturada na literatura dos anos de 1970, com suporte em abordagens psicológicas e sociológicas (DUTRA et al., 2009). $\mathrm{Na}$ visão tradicional, a carreira é intimamente associada à realização pessoal, ancorada em estruturas hierárquicas rígidas, na qual o sucesso é reconhecido por meio de promoções e de aumento salarial. Na perspectiva não tradicional, o trabalhador assume uma posição mais ativa e enfatiza o autogerenciamento da carreira não limitada a uma única organização (BARUCH, 2002).Diante dessa concepção, "seja por razões externas, como novas tecnologias e mudanças no mercado, ou por razões internas, como necessidades e valores pessoais, uma pessoa pode começar a explorar um terreno ou atividade, em qualquer estágio de carreira e de seu ciclo de vida" (DUARTE; SILVA, 2013, p. 739).

De forma ilustrativa, são apresentados cinco modelos de carreira, presentes na literatura (Quadro 1). São elas: a carreira sem fronteiras; a proteana; a craftcareer; a portfólio e a carreira multidirecional, como segue:

Quadro 1:Modelos de carreira encontrados na literatura científica da área

\begin{tabular}{|l|l|l|}
\hline \multicolumn{1}{|c|}{ Modelo } & Principais autores & \multicolumn{1}{c|}{ Proposições } \\
\hline Carreira sem & Arthur (1994) e & Pluralidade de contextos de trabalho \\
\cline { 3 - 3 } fronteiras & $\begin{array}{l}\text { Arthur e Rousseou } \\
(1996)\end{array}$ & Declínio das carreiras organizacionais \\
\cline { 3 - 3 } & Hall (1976, 2002) & Competências (Know-why, Know-how e Know-whom) \\
\cline { 3 - 3 } \multirow{2}{*}{\begin{tabular}{l} 
Carreira \\
\cline { 3 - 3 }
\end{tabular}} & & Variedade de experiências \\
\cline { 3 - 3 } & & Adaptabilidade e resiliência \\
\cline { 3 - 4 } & & Identidade como âncora \\
\hline
\end{tabular}

Revista Eletrônica Gestão e Serviços v.9, n. 1, pp. 2164-2189, Janeiro/Junho 2018.

ISSN Online: 2177-7284 e-mail: regs@ metodista.br 
BIZZARIA; TASSIGNY; FROTA; MOURA; BEZZERRA

\begin{tabular}{|c|c|c|}
\hline \multirow[t]{3}{*}{ Craftcareer } & \multirow{3}{*}{$\begin{array}{l}\text { Poehnell, } \\
\text { Amundon e Reuter } \\
\text { (2002) }\end{array}$} & $\begin{array}{l}\text { Autonomia, criatividade, invenção e reinvenção do próprio } \\
\text { trabalho }\end{array}$ \\
\hline & & Sujeito e atividade como um único conjunto \\
\hline & & Trabalho e sensemaking \\
\hline \multirow{3}{*}{$\begin{array}{l}\text { Carreira } \\
\text { portfólio }\end{array}$} & \multirow{3}{*}{$\begin{array}{l}\text { Borgen, Amundon } \\
\text { e Reuter (2004) }\end{array}$} & Diversificação das atividades profissionais \\
\hline & & Flexibilização das identidades pessoais \\
\hline & & Múltiplas zonas de expertise individual \\
\hline \multirow{3}{*}{$\begin{array}{l}\text { Carreira } \\
\text { multidirecional }\end{array}$} & \multirow{3}{*}{$\begin{array}{l}\text { Baruch } \quad(2004, \\
2006)\end{array}$} & Não linearidade das experiências de trabalho \\
\hline & & Contrato psicológico transacional \\
\hline & & Comprometimentos múltiplos \\
\hline
\end{tabular}

Fonte: Magalhães e Bendassolli (2013, p. 441).

A carreira proteana, que marcou a década de 1970 por meio dos estudos de Hall (2002), enfatiza a postura do sujeito como gerenciador de sua carreira, conforme a habilidade de mudar em função do próprio desejo, característica semelhante à do deus grego do mar, Proteus. Por sua vez, a carreira sem fronteiras, que marcou os anos de 1990, inaugurou a concepção de flexibilização inerente à ideia de nova economia em que a ênfase está no desenvolvimento pessoal (ROCRA et al.,2013). As carreiras craftcareer, portifólio e multidimensional são expressões que denotam as carreiras emergentes. A primeira, postula que a carreira deve se assemelhar a uma obra de arte, em que o artesão lida com sua obra como sendo inacabada e sempre aberta à intervenção ou à transformação. A segunda, expressa a reunião de um conjunto de atividades diversificadas, que habilitam o trabalhador a atuar em variadas áreas. Por último, a multidimensional compreende carreiras dinâmicas e abertas a possibilidades, que dão contornos a objetivos e metas em constante transformação ao longo do tempo (MAGALHÃES; BENDASSOLLI, 2013).

Nos anos de 1990, a ideia de carreira se associa fortemente à perspectiva de flexibilização e de novos perfis profissionais, exigindo carreiras mais fluidas e adaptáveis às mudanças no mercado de trabalho, com a perspectiva de movimento, não linearidade e ausência de estabilidade (DUARTE; SILVA, 2013). Diante disso, as organizações e os trabalhadores iniciaram o processo de planejamento de carreiras com suporte no desenvolvimento pessoal, possibilitando aos sujeitos uma variabilidade de conteúdos necessários ao bom desempenho em várias organizações e, assim, aumentando a probabilidade de sucesso (ROCHA et al., 2013).

Durante os anos seguintes, estudos avançaram na direção de uma abordagem Revista Eletrônica Gestão e Serviços v.9, n. 1, pp. 2164-2189, Janeiro/Junho 2018. ISSN Online: 2177-7284 e-mail: regs@ metodista.br 
categorial, deixando de seguir padrões tradicionais para ressaltar a ideia de trajetórias dos sujeitos em suas diversas fases da vida-trabalho "priorizam aspectos distintos da carreira, como: a renda e o status; a segurança com base na empregabilidade; a aprendizagem e o desenvolvimento de competências; a satisfação pessoal, o reconhecimento e equilíbrio entre a carreira e as demais arenas da vida" (COSTA, 2010, p. 38), sendo que uma das abordagens da análise dos momentos da carreira tem como referência a concepção de sucesso na carreira (COSTA, 2010, 2014).

Nesse sentido, a carreira vista sob a ótica do sucesso é definida como resultado de um processo formativo que envolve aspectos psicológicos e profissionais que emergem do contexto de atividades laborais, considerando que as metas e expectativas pessoais são desejáveis e avaliadas de forma positiva pelo próprio sujeito (JUDGE et al., 1995,ARTHUR; KHAPOVA; WILDEROM, 2005, COSTA, 2014). Dessa forma, a definição de sucesso na carreira privilegia o aspecto dinâmico inerente a um construto social, fruto de um contexto histórico cultural que delimita seu entendimento e alcance (DRIES; PEPERMANS; CARLIER, 2008). Além disso, a composição de uma carreira revela um construto de várias dimensões que é influenciado na ordem psicológica, social e econômica, apresentadas no momento atual, bem como, no acúmulo do ciclo de vida do formando universitário(MAGALHÃES; BENDASSOLLI, 2013).

Diante de um conceito dinâmico e com suporte na leitura de Judge et al. (1995), constata-se que o sucesso na carreira possui duas características interdependentes: os aspectos subjetivo e o objetivo. "A carreira objetiva reflete a sequência de posições e dos papéis ocupados pelo indivíduo ao longo da vida de trabalho, ou seja, é definida a partir do conjunto de prescrições objetivas dadas pela divisão técnica do trabalho e pela organização" (MAGALHÃES, BENDASSOLLI, 2013, p. 437). Por sua vez e de forma subjetiva, a carreira faz referência à apresentação dos papéis e das experiências acumuladas por parte do formando, gerando significado nas atividades desempenhadas, para quem exerce uma atividade profissional (MAGALHÃES; BENDASSOLLI, 2013).

Além do aspecto subjetivo-objetivo, variadas dimensões e critérios são utilizados na avaliação da carreira, como: dinheiro e posição, ascensões, alcance de metas, adaptabilidade e capacidade de atuar em atividades mais complexas, identidade com o trabalho, empregabilidade, equilíbrio vida-trabalho, realização pessoal, sentimento de orgulho e reconhecimento (HALL, 2002; STURGES; GUEST, 2004; STURGES, 2008; CLARKE, 2008). 
Com suporte nessas dimensões, alguns modelos de sucesso de carreira foram elaborados, como o modelo multidimensional de Dries, Pepermans e Carlier (2008), referência para as proposições futuras de instrumentos para análise de carreira, englobando, também, itens que não estavam comtemplados no modelo, por exemplo, os estudos de Cornelius e Skinner (2008) e Clarke (2008).

Parte-se do pressuposto de que a carreira é mais bem avaliada por meio da própria interpretação dos sujeitos envolvidos e que depende, em grande parte, do modo como o indivíduo percebe o mercado de trabalho, tendo como passo introdutório seu próprio comportamento de carreira, o que evidencia de forma mais contundente do que as condições subjetivas do formando universitário (MAGALHÃES; TEIXEIRA, 2013).

Constata-se que a percepção, como um construto central para o sucesso na carreira, é aspecto preponderante para a avaliação e decisões derivadas, no sentido de que a apreensão de seus sentidos particulares dão subsídios aos novos posicionamentos, diante da busca por realização na sua própria trajetória profissional (COSTA, 2010; ROCHA, 2013).

Assim, Costa $(2010,2014)$ desenvolveu estudos que geraram a Escala de Percepção de Sucesso na Carreira,construída e validada em 2010 e 2011, como instrumento de pesquisa utilizado pelo presente estudo.

\section{METODOLOGIA}

Esta é uma pesquisa teórica e empírica, de abordagem quantitativa, do tipo levantamento ou survey (RICHARDSON, 1999; COLLIS, HUSSEY, 2006), com dados coletados em uma amostra não probabilística de alunos de cursos de graduação (Enfermagem, Farmácia, Fisioterapia, Administração, Comércio Exterior, Ciências Contábeis, Economia, Jornalismo, Áudio Visual e outras mídias, Publicidade, Ciências Tecnológicas, Petróleo e Gás, Ciências Jurídicas, Direito e Física) de uma Instituição de Ensino Superior privada, situada em Fortaleza-CE. A pesquisa contou com uma de amostra de 105 alunos, distribuídos em todos os semestres letivos, de acordo com o critério de possuir algum tipo de experiência de trabalho. Esse requisito foi definido em função do instrumento de pesquisa, que privilegia a percepção de carreira, com aporte na vivência concreta de trabalho. 
Quadro 2 - Cursos de graduação por área de conhecimento

\begin{tabular}{|c|c|c|c|c|c|}
\hline $\begin{array}{l}\text { Área } \\
\text { Curso }\end{array}$ & $\begin{array}{c}\text { Ciências Sociais } \\
\text { Aplicadas }\end{array}$ & $\begin{array}{c}\text { Ciências da } \\
\text { Comunicação }\end{array}$ & $\begin{array}{l}\text { Ciências da } \\
\text { Saúde }\end{array}$ & Outros & TOTAL \\
\hline Curso & $\begin{array}{l}\text { Administração } \\
\text { Comércio exterior } \\
\text { Ciências contábeis } \\
\text { Economia }\end{array}$ & $\begin{array}{l}\text { Jornalismo } \\
\text { Áudio Visual e } \\
\text { outras mídias } \\
\text { Publicidade }\end{array}$ & $\begin{array}{l}\text { Enfermagem } \\
\text { Farmácia } \\
\text { Fisioterapia }\end{array}$ & $\begin{array}{l}\text { Petróleo e } \\
\text { gás } \\
\text { Direito } \\
\text { Física }\end{array}$ & \\
\hline $\begin{array}{l}\text { Quantidade } \\
\text { de alunos }\end{array}$ & 61 & 31 & 8 & 5 & 105 \\
\hline
\end{tabular}

Fonte: Dados da pesquisa (2016).

Com a intenção de analisar a percepção sobre sucesso na carreira, foi utilizado como instrumento de pesquisa a Escala de Percepção de Sucesso na Carreira (EPSC), composta por 10 itens, em sua versão reduzida,distribuídos em duas dimensões (subjetiva e objetiva) associados a uma escala de cinco pontos que varia de "discordo totalmente", para o número 1, e "concordo totalmente", para o número 5. Como a versão reduzida é apresentada no escopo de sua versão completa, os itens fazem referência à sua localização em função da versão de 48 questões.

Quadro 3 - Definições das dimensões da EPSCR em sua versão reduzida.

\begin{tabular}{|c|c|c|}
\hline Dimensão & Definição & Itens \\
\hline Objetiva & $\begin{array}{l}\text { Envolve resultados que os outros } \\
\text { conhecem e normalmente usam } \\
\text { para avaliar a carreira da pessoa, } \\
\text { como remuneração e status } \\
\text { hierárquico. }\end{array}$ & $\begin{array}{l}\text { V2 -Tenho recebido recompensas justas comparadas } \\
\text { com as de outras pessoas que conheço (não só na } \\
\text { minha área). } \\
\text { V4 -A remuneração que recebo por minhas atividades } \\
\text { profissionais é justa, pelo que já investi na carreira. } \\
\text { V17 -Estou tranquilo sobre meu futuro, quanto às } \\
\text { minhas necessidades financeiras e materiais. } \\
\text { V43 -O prestígio (ou status) profissional da minha } \\
\text { posição hierárquica está de acordo com meus } \\
\text { interesses. } \\
\text { V48 -Minha renda supre as minhas necessidades e as } \\
\text { de meus dependentes. }\end{array}$ \\
\hline Subjetiva & $\begin{array}{l}\text { Envolve resultados que têm valor } \\
\text { para a própria pessoa, } \\
\text { independentemente dos resultados }\end{array}$ & $\begin{array}{l}\text { V10 - Tenho orgulho do que faço profissionalmente. } \\
\text { V23 - Os trabalhos que executo compreendem grande } \\
\text { variedade de tarefas. }\end{array}$ \\
\hline
\end{tabular}

Revista Eletrônica Gestão e Serviços v.9, n. 1, pp. 2164-2189, Janeiro/Junho 2018.

ISSN Online: 2177-7284 e-mail: regs@ metodista.br 
BIZZARIA; TASSIGNY; FROTA; MOURA; BEZZERRA

\begin{tabular}{|l|l|l|}
\hline que as outras pessoas conhecem & V24 -Estou constantemente aprendendo e me \\
sobre sua carreira, tais como & desenvolvendo em minha carreira. \\
sentir-se competente, gostar e ter & V25 -Tenho criado inovações importantes durante \\
orgulho do que faz, estar em & minha carreira profissional. \\
constante desenvolvimento, & V38 - Os trabalhos que desenvolvo atualmente em \\
inovar e realizar atividades & minha carreira exigem um alto nível de competência. \\
gratificantes. & \\
\hline
\end{tabular}

Fonte: Adaptado de Costa (2014, p. 292).

A escala foi aplicada, neste estudo,de forma individualizada, a cada sujeito da amostra. Os dados foram coletados por meio de visitas às salas de aula, com o consentimento prévio e apoio do professor responsável. Para a tabulação, foi utilizada a planilha Excel importada para o software StatisticalPackage for theSocial Sciences(SPSS), versão 22.

A pesquisa teve uma proporção de 10,5 respondentes por variável, considerando 105 respondentes para 10 variáveis. Esse quantitativo amostral atende à recomendação de Hair et al. (2009), que sugere o mínimo aceitável de cinco vezes mais observações do que o número de variáveis e amostras maiores que 100 observações. Por sua vez, a margem de erro utilizada para o presente estudo foi de $5 \%(0,05)$, conferindo $95 \%$ de confiabilidade. Esse percentual é utilizado com maior frequência, mesmo que seja possível escolher valores entre 3\% e 10\%, dependendo do questionário (STEVENSON, 2001).

O tratamento dos dados, inicialmente, buscou identificar e analisar os missing values (valores perdidos), com o objetivo de identificar os padrões existentes nos dados perdidos que caracterizem esse processo. Nessa fase, o pesquisador deve tomar a decisão de ignorar, ou não, os dados que acontecem aleatoriamente nas variáveis (HAIR et al., 2009).

Para buscar analisar a percepção de sucesso de carreira dos discentes, optou-se por duas técnicas multivariadas interdependentes: Análise Fatorial (AF) exploratória, como forma de apreender a estrutura das inter-relações entre as variáveis em busca da estrutura multidimensional subjacente aos dados, tendo em vista os resultados dos testes Kaiser-Meyer-Okin (KMO), e o de esfericidade de Bartlett, Rotated Commponente Matrix (HAIR et al. 2009), e a Análise de Agrupamentos, ou Análise de Cluster (AC), que permite o reconhecimento de padrões. Os agrupamentos devem atender aos 
requisitos de maior homogeneidade interna (dentro dos agrupamentos) e heterogeneidade externa (entre agrupamentos) (HAIR et al., 2009).

No que tange à AF, para identificação das cargas fatoriais significantes seguiu-se o critério de Hair et al. (2009), que estabelece 0,4 como carga fatorial significante para classificar a distribuição das variáveis entre as dimensões. Realizou-se a AF com referência à extração componente principal, com tipo de rotação ortogonal pelo método Varimax (HAIR et al., 2009).

Para realizar a Análise de Cluster (AC), utilizou-se, inicialmente, o procedimento hierárquico de agrupamento, com suporte na leitura do Dendograma formado pelo algoritmo aglomerativo complete linkage (furthestneighbor). Utilizou-se como medida de similaridade a distância euclidiana quadrática, para escolha do número de grupos que atendessem ao critério da homogeneidade (inter) e heterogeneidade (inter), tendo como referência a observação de grandes alterações dos níveis de similaridade para as sucessivas fusões, definido como regra de parada (stoppingrule), com base na avaliação da variação de heterogeneidade entre soluções de agrupamentos (HAIR et al., 2009).

Assim, com a definição de quatro grupos, realizou-se o método não hierárquico (K-means cluster), a partir dos centroides obtidos no complete linkage, com a finalidade de, por meio da análise de variância (teste ANOVA), verificar se existem diferenças significativas entre as variáveis e, assim, selecionar as variáveis que possuem significância estatística ao nível de 5\% para a formação dos grupos. Por fim, novo Dendograma foi solicitado, com a configuração dos grupos definidos e com as variáveis significativas. Além disso, com os agrupamentos definidos, realizou-se o cruzamento dos grupos com o perfil dos alunos da pesquisa, com base na área de conhecimento, semestre letivo e tempo de experiência de trabalho.

\section{RESULTADOS}

Os resultados dos testes KMO e o de esfericidade de Bartlett (Tabela 1), indicados como critérios de referência para analisar a viabilidade da Análise Fatorial (AF) (Tabela 2), explicitam informações sobre o teste do modelo em estudo.

Tabela 1- Testes KMO e o de esfericidade de Bartlett 


\begin{tabular}{l|l|r}
\hline \multicolumn{2}{l|}{$\begin{array}{l}\text { Medida Kaiser-Meyer-Olkin de adequação de } \\
\text { amostragem. }\end{array}$} &, 556 \\
\hline Teste de esfericidade de & Aprox. Quiquadrado & 133,164 \\
\cline { 2 - 3 } Bartlett & df & 45 \\
\cline { 2 - 3 } & Sig. &, 000 \\
\hline Fonte: Dados da pesquisa (2015).
\end{tabular}

Algumas estatísticas são consideradas para o teste de conveniência do modelo Fatorial (MALHOTRA, 2012).O teste de esfericidade de Barlett (BTS) indica se existe relação suficiente entre os indicadores para aplicação da Análise Fatorial (AF) (BEZERRA, 2009). A estatística Quiquadrado aproximada, 133,164com 45 graus de liberdade, é significativa ao nível de 0,05. (BEZERRA, 2009). Por sua vez, a medida de adequação da amostra de Kaiser-Meyer-Olkin (KMO) compara as magnitudes dos coeficientes de correção observados com as magnitudes dos coeficientes de correlação parcial (Measureof Sampling Adequacy) (BEZERRA, 2009). Pequenos valores da estatística KMO indicam que as correlações entre pares de variáveis não podem ser explicadas por outras variáveis e que a AF pode ser inapropriada (MALHOTRA, 2012). Apesar do valor de KMO ser limite em relação ao valor de 0,5 , referência para uma boa explicação entre dimensões e variáveis, a significância $(0,000, \mathrm{p}<0,05)$ indica que há relação suficiente entre os indicadores para a aplicação da AF (BEZERRA, 2009).

Tabela 2 - Determinação do total de dimensões representantes das variáveis daEPSCR.

\begin{tabular}{l|r|r|r|r|r|r}
\hline \multirow{2}{*}{ Componente } & \multicolumn{7}{c}{ Variância total explicada } \\
\cline { 2 - 7 } & Total & \% de variância & \% cumulativa & Total & \% de variância & \% cumulativa \\
\hline 1 & 1,982 & 19,816 & 19,816 & 1,706 & 17,057 & 17,057 \\
\hline 2 & 1,836 & 18,362 & 38,178 & 1,588 & 15,881 & 32,938 \\
\hline 3 & 1,253 & 12,535 & 50,713 & 1,535 & 15,352 & 48,290 \\
\hline 4 & 1,158 & 11,579 & 62,291 & 1,400 & 14,001 & 62,291 \\
\hline 5 &, 894 & 8,942 & 71,234 & & & \\
\hline 6 &, 767 & 7,674 & 78,907 & & & \\
\hline 7 &, 626 & 6,257 & 85,164 & & & \\
\hline 8 &, 575 & 5,745 & 90,909 & & & \\
\hline 9 &, 389 & 3,886 & 100,000 & & & \\
\hline 10 & & & & & & \\
\hline
\end{tabular}

Revista Eletrônica Gestão e Serviços v.9, n. 1, pp. 2164-2189, Janeiro/Junho 2018.

ISSN Online: 2177-7284 e-mail: regs@ metodista.br 


\section{BIZZARIA; TASSIGNY; FROTA; MOURA; BEZZERRA}

Método de Extração: Análise de Componente Principal.

Fonte: Dados da pesquisa (2016).

A técnica mais comumente usada para se definir o número de fatores a extrair é o critério da raiz latente, ou autovalor (eigenvalue), que corresponde a quanto a dimensão consegue explicar da variância (HAIR et al. 2009; MALHOTRA, 2012; BEZERRA, 2009). Apenas fatores que têm autovalores acima de 1,0 são considerados significantes. Além disso, considera-se o percentual mínimo de explicação da variância apropriado o valor de $60 \%$. Assim, os dados sugerem que quatro fatores conseguem explicar 62, $291 \%$ das variáveis.

As informações da Tabela 3 apontam a relação entre as dimensões e as variáveis, em função das maiores correlações. Utilizaram-se,como parâmetro, as cargas fatoriais significantes como aquelas maiores que 0,4(HAIR et al., 2009).

Tabela 3 - Matriz rotacionada dos componentes dos fatores de Clima Organizacional.

\begin{tabular}{|c|c|c|c|c|}
\hline \multicolumn{5}{|l|}{ Matriz de componente rotativa ${ }^{a}$} \\
\hline & \multicolumn{4}{|c|}{ Componente } \\
\hline & 1 & 2 & 3 & 4 \\
\hline $\begin{array}{l}\text { V2-Tenho recebido recompensas justas comparadas com as de outras pessoas que } \\
\text { conheço (não só na minha área) }\end{array}$ & ,712 &, 075 & ,225 & 042 \\
\hline $\begin{array}{l}\text { V4-A remuneração que recebo por minhas atividades profissionais é justa, pelo } \\
\text { que já investi na carreira }\end{array}$ & ,828 &,- 188 &, 001 & ,057 \\
\hline V10-Tenho orgulho do que faço profissionalmente & ,090 &,- 120 & ,859 &,- 103 \\
\hline $\begin{array}{l}\text { V17-Estou tranquilo sobre meu futuro, quanto às minhas necessidades financeiras } \\
\text { e materiais }\end{array}$ &,- 052 &,- 118 &, 021 & ,796 \\
\hline V23-Os trabalhos que executo compreendem grande variedade de tarefas &,- 180 & ,814 &,- 136 &,- 041 \\
\hline V24-Estou constantemente aprendendo e me desenvolvendo em minha carreira &,- 473 & ,054 & ,485 & ,341 \\
\hline V25-Tenho criado inovações importantes durante minha carreira profissional & 138 & ,329 & ,523 & 058 \\
\hline $\begin{array}{l}\text { V38 - Os trabalhos que desenvolvo atualmente em minha carreira exigem um alto } \\
\text { nível de competência }\end{array}$ &, 030 & ,763 & , 193 &,- 053 \\
\hline $\begin{array}{l}\text { V43 - O prestígio (ou status) profissional da minha posição hierárquica está de } \\
\text { acordo com meus interesses }\end{array}$ &,- 028 & ,402 & ,399 & ,485 \\
\hline V48 -Minha renda supre as minhas necessidades e as de meus dependentes & ,475 &,- 021 &,- 152 & ,625 \\
\hline
\end{tabular}

Método de Extração: Análise de Componente Principal.

Método de Rotação: Varimax com Normalização de Kaiser. ${ }^{a}$

a. Rotação convergida em 6 iterações.

Fonte: Dados da pesquisa (2016). 
A matriz rotacionada permite a classificação das variáveis em cada uma das dimensões. O agrupamento das dimensões em função das maiores correlações apresentadas deve guiar a nomenclatura escolhida e a análise teórica que fundamentará a estrutura subjacente aos dados e identificada por meio da Análise Fatorial (AF). A primeira dimensão 1 , responsável por $17,05 \%$ da variância explicada, se correlacionou fortemente com a V2, e com a V4, sendo a V4 a variável que melhor representa a dimensão, com carga fatorial 0,82. A segunda, responsável por 15,88\% da variância explicada, se correlacionou fortemente com V23 e com a V38, a primeira possuindo maior correlação com as dimensões, em função da carga fatorial 0,81, em comparação com 0,76 da V38. A terceira dimensão responsável por 15,35\% da variância explicada, correlacionou-se fortemente com a V10, e com a V24 e V25. A principal variável dessa dimensão é a V10, com 0,85 de carga fatorial. A última, representando por 14,00\% da variância explicada, correlacionou-se mais intensamente com as variáveis V17, V43 e V48. Dessas, a V17 possui maior correlação. Ressalta-se que as variáveis V24, V43 e V48 têm valores de carga fatorial significativas (acima de 0,4) em mais de uma dimensão. No entanto, definiu-se a maior carga para inclusão na respectiva dimensão.

No que diz respeito à Análise de Cluster (AC), o método não hierárquico é utilizado para gerar o agrupamento de variáveis expresso no dendograma (Figura 2),que representa um conjunto preliminar de soluções como base para estabelecer o número apropriado de agrupamentos. Nessa etapa, a solução quadripartite contempla diferenças entre variáveis e, também, a escolha da pesquisa em função da estrutura quadridimensional obtida pela AF, com suporte na distância redimensionada ao redor de 10 , regra de parada (stoppingrule).

Figura 1 - Dendograma

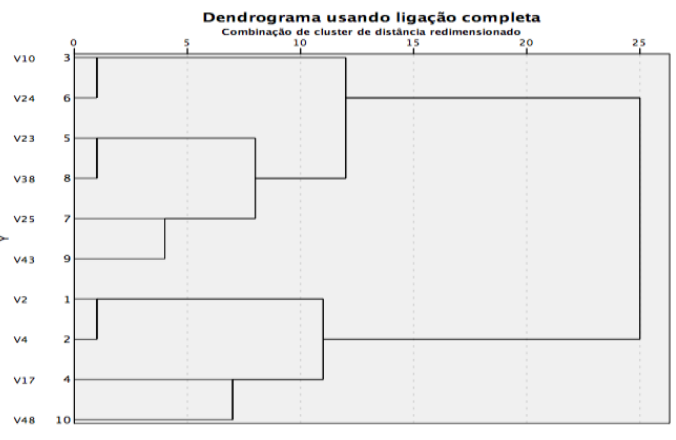

Fonte: Dados da pesquisa (2016). 
O método não hierárquico é processado como forma de refinar a solução encontrada. Após a escolha da definição dos grupos para o estudo, processaram-se duas análises de variância (ANOVA). A primeira indicou que a variável 24 não possui diferença significativa para a formação dos grupos (sig 0,08 > 0,05). A segunda (Tabela 4) demonstra que todas as demais variáveis possuem significância estatística, no sentido de indicar diferença entre os grupos e, por isso, são as variáveis consideradas para a definição dos grupos.

Tabela 4 - Teste de Variância ANOVA

\begin{tabular}{|c|c|c|c|c|c|c|}
\hline & \multicolumn{2}{|l|}{ Cluster } & \multicolumn{2}{|l|}{ Erro } & \multirow[b]{2}{*}{ Z } & \multirow[b]{2}{*}{ Sig. } \\
\hline & Quadrado Médio & $\mathrm{df}$ & Quadrado Médio & $\overline{\mathrm{df}}$ & & \\
\hline $\mathrm{V} 2$ & 5,160 & 3 & ,885 & 101 & 5,828 &, 001 \\
\hline V4 & 24,862 & 3 & ,905 & 101 & 27,480 & $\overline{0}, 000$ \\
\hline V10 & 5,721 & 3 & ,578 & 101 & 9,895 & ,000 \\
\hline V17 & 20,303 & 3 & 808 & 101 & 25,123 & $\overline{0}$ \\
\hline V23 & 3,731 & 3 & 954 & 101 & 3,910 & 011 \\
\hline V25 & 5,759 & 3 & 869 & 101 & 6,627 & ,000 \\
\hline V38 & 13,287 & 3 & 9667 & 101 & 13,736 & $\overline{0}, 000$ \\
\hline V43 & 25,666 & 3 & ,840 & 101 & 30,551 & ,000 \\
\hline V48 & 22,413 & 3 & 1,304 & 101 & 17,182 & , 000 \\
\hline
\end{tabular}

Fonte: Dados da pesquisa (2016).

Realizou-se um novo cluster hierárquico, para a observação do novo dendograma gerado após a exclusão da variável não significativa V24 (Figura 2)

Figura 2 - Dendograma de análise hierárquica de agrupamentos reespecificada

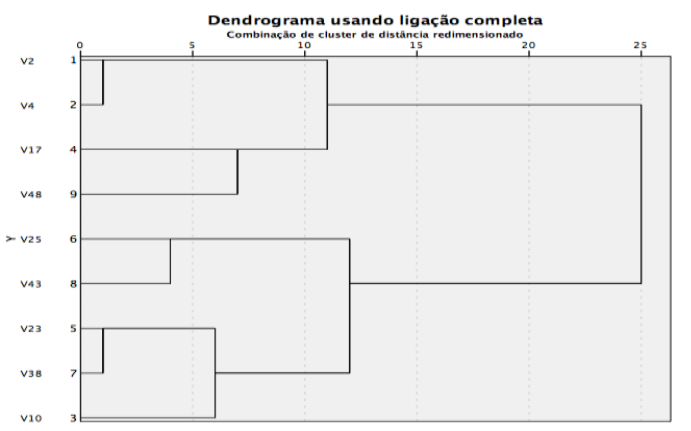

Fonte: Dados da pesquisa (2016).

Os grupos foram dispostos da seguinte forma: grupo 1, formado pelas variáveis 
V2 e V4; grupo 2, formado pelas variáveis V17 e V48; grupo 3, formado pelas variáveis V25 e V43; e grupo 4, formado pelas variáveis V38 e V10.

A Tabela 5apresenta o cruzamento dos grupos formados com uma das informações solicitadas no instrumento de pesquisa, no caso, curso vinculado, que foi agrupada em áreas de conhecimento.

Tabela 5 - Cruzamento Área de Conhecimento por cluster

\begin{tabular}{|c|c|c|c|c|c|c|}
\hline & & \multicolumn{5}{|c|}{ Área de Conhecimento } \\
\hline \multicolumn{2}{|c|}{ Número de cluster } & $\mathbf{C C} *$ & CS** & $\mathbf{C S A} * * *$ & Outras & Total \\
\hline \multirow[t]{2}{*}{1} & $\mathrm{~N}$ & 3 & 0 & 14 & 0 & 17 \\
\hline & $\%$ & $17,6 \%$ & $0,0 \%$ & $82,4 \%$ & $0,0 \%$ & $100,0 \%$ \\
\hline \multirow[t]{2}{*}{2} & $\mathrm{~N}$ & 25 & 4 & 10 & 4 & 43 \\
\hline & $\%$ & $58,1 \%$ & $9,3 \%$ & $23,3 \%$ & $9,3 \%$ & $100,0 \%$ \\
\hline \multirow[t]{2}{*}{3} & $\mathrm{~N}$ & 1 & 3 & 17 & 1 & 22 \\
\hline & $\%$ & $4,5 \%$ & $13,6 \%$ & $77,3 \%$ & $4,5 \%$ & $100,0 \%$ \\
\hline \multirow[t]{2}{*}{4} & $\mathrm{~N}$ & 2 & 1 & 20 & 0 & 23 \\
\hline & $\%$ & $8,7 \%$ & $4,3 \%$ & $87,0 \%$ & $0,0 \%$ & $100,0 \%$ \\
\hline \multirow[b]{2}{*}{ Total } & $\mathrm{N}$ & 31 & 8 & 61 & 5 & 105 \\
\hline & $\%$ & $29,5 \%$ & $7,6 \%$ & $58,1 \%$ & $4,8 \%$ & $100,0 \%$ \\
\hline
\end{tabular}

*Ciências da Comunicação

** Ciências da Saúde

***Ciências Sociais Aplicadas

Fonte: Dados da pesquisa (2016).

A Tabela 5 discrimina a quantidade de casos por cluster (cluster 1, com 17 casos, cluster 2, com 43 casos, cluster 4 , com 22 casos e cluster 4 , com 23 casos) e apresenta a distribuição dos 105 respondentes por área e por cluster.

Percebe-se que a área CC possui uma maior participação no cluster 2, 58,1\%, em comparação com a sua participação nos demais grupos (17,6\% no cluster 1, 4,5\% no cluster 3 e 8,7\% no cluster 4) e, também, possui a maior participação em relação às outras áreas (9,3\% da área de CS, 23,3\% da área de CSA e 9,3\% de outras áreas). Dessa forma, pode-se afirmar que o cluster 2 possui como característica a predominância de alunos oriundos de cursos da área de CC, especificamente, Jornalismo, Publicidade e Áudio Visual e outras mídias.

A área de CSA possui importante participação em dois grupos: cluster 1 e cluster 
4. Na formação do cluster 4,a CSA tema maior participação, 87,0\%, em comparação com a sua participação nos demais grupos $(82,4 \%$ no cluster $1,23,3 \%$ no cluster 2 e $77,3 \%$ no cluster 3). Também possui a maior participação no cluster 4 em relação as outras áreas (8,7\% da área CC, 4,3\% da área de CS e 0,0\% de outras áreas). Pode-se, então, afirmar que o cluster 4 tem predominância dos cursos da área de CSA, nesta pesquisa, formados pelos cursos de Administração, Economia, Comércio Exterior e Ciências Contábeis.

No que tange à relação da CSA com o cluster 1, observa-se que a área possui sua segunda maior participação, $82,4 \%$, em comparação com a sua participação nos demais grupos (23,3\% no cluster 3, 77,3\% no cluster 3 e 87,0\% no cluster 4). Entretanto, é a maior participação observada no cluster 1 em comparação com as demais áreas $(17,6 \%$ da área de CC, 0,0\% da área de CS e 0,0\% de outras áreas). Dessa forma, a área de CSA tem predominância tanto no cluster 4 , como no cluster 1 .

A área de CS possui maior participação no cluster 3, 13,6\%, em comparação com a sua participação nos demais grupos ( $0,0 \%$ no cluster $1,9,3 \%$ no cluster 2 e 4,3\% no cluster 4). Observa-se, também, que a área tem a segunda maior participação em relação às outras áreas $(4,5 \%$ da área de CC, 77,3\% da área de CSA e 4,5\% de outras áreas). Percebe-se,porém, que a área de maior predominância no cluster 3 é, também, a área de CSA.

\section{DISCUSSÃO}

A conclusão de um curso universitário é fator de intensa expectativa diante do futuro profissional, como consequência dos desafios do mundo do trabalho em interação com áreas de atuação cada vez mais complexas. "Onde trabalhar, ou em qual área profissional focar os estudos são um pequeno exemplo de questionamentos que podem surgir à medida que a formação universitária encaminha-se para o final" (MAGALHÃES, BENDASSOLLI, 2013, p. 434). Assim, a percepção sobre a carreira se configura como elementar e está relacionada à elaboração de um projeto de vidatrabalho em função de expectativas, oportunidades e alternativas profissionais de sucesso (TEIXEIRA; GOMES, 2005; COSTA 2010).

Nesse sentido, o estudo estruturou a percepção de sucesso na carreira de discentes de forma quadridimensional. A primeira dimensão, formada por variáveis 
relacionadas ao estudo de Costa (2014) numa perspectiva objetiva, reúne a percepção direta de recompensa e de remuneração como requisitos de avaliação de carreira. Tal achado corrobora os conhecimentos construídos a partir da leitura de obras que abordam os aspectos responsáveis pelo impacto salarial, vistos como os primeiros requisitos quando diante de análises de carreira.

A segunda dimensão, que confere um desmembramento da dimensão subjetiva de Costa (2014), é representada pela abrangência da complexidade do trabalho, que envolve a variedade de tarefas e o nível de competência necessário para executá-las. As múltiplas tarefas cotidianas exigem dos novos profissionais flexibilidade em suas formas de conceber carreira. As competências, que parecem caminhar para a busca constante de novas habilidades, se alinham a essa dimensão, por trazer à tona um lugar privilegiado para a complexidade do trabalho em interface com as novas configurações de carreira no ambiente universitário, que é, por excelência, o lugar não só de formação, mas de desconstrução e problematização em função das novas demandas econômicas, sociais e culturais.

A terceira dimensão, formada, também, pelo desmembramento da dimensão subjetiva de Costa (2014) configura carreira como um lugar de bem-estar, de forma que o crescimento pessoal no trabalho "deve" alinhar-se à emergência de sentimentos positivos relacionados ao orgulho e à autonomia, que favorecem o aprendizado e a criatividade.

Por fim, a quarta dimensão é representada pelo desmembramento da dimensão objetiva de Costa (2014). Forma-se em torno dela a leitura de carreira na perspectiva de um futuro promissor, no que diz respeito ao atendimento das necessidades financeiras e materiais da família e ao atendimento das expectativas em torno de status social.

Pensara carreira na perspectiva das áreas de conhecimento pode, também, especificar o discurso em torno do que atinge esses cursos e, assim, formar estratégias específicas para acompanhar os alunos nas suas definições sobre carreira, e sua interface com a ideia de sucesso, bem como, promover espaços vivenciais para que discentes e docentes possam buscar os objetivos e os sentidos de "estar" na academia em curto, médio e longo prazos. O Quadro 4 descreve a relação entre os clusters, as variáveis do estudo, a área predominante e os fatores extraídos do estudo.

Quadro 4 - Relação do estudo fatorial com a formação dos grupos 
BIZZARIA; TASSIGNY; FROTA; MOURA; BEZZERRA

\begin{tabular}{|l|l|l|l|}
\hline Formação dos Clusters & Variáveis & Área predominante & Fatores \\
\hline Cluster 1 & V2, V4 & CSA & F1 \\
\hline Cluster 2 & V17, V48 & CC & F4 \\
\hline Cluster 3 & V25, V43 & CSA & F3/F4 \\
\hline Cluster 4 & V23, V38, V10 & CSA & F2/F3 \\
\hline
\end{tabular}

Fonte: Dados da pesquisa (2016).

Percebe-se que o segundo grupo, com a formação predominante dos cursos da área de Ciências da Comunicação (CC), agrega as variáveis que formam o fator 4 , ou seja, a dimensão que organiza a compreensão sobre carreira em torno da leitura sobre o futuro. Assim, neste estudo, supõe-se que os alunos vinculados à área $\mathrm{CC}$ tendem a interpretar sucesso na vida profissional com suporte na percepção de uma carreira que seja sustentável em um longo prazo.

\section{CONSIDERAÇÕES FINAIS}

Com o objetivo de dimensionar a percepção de sucesso na carreira de Universitários inseridos no mercado de trabalho, este estudo identificou uma estrutura quadridimensional, formada pelas dimensões, em ordem decrescente de importância, Impacto da Renda, Complexidade do Trabalho, Bem-estar no Trabalho e Perspectiva de futuro.

Como o estudo foi desenvolvido com alunos universitários, a pouca inserção ou pouca maturidade em relação à carreira pode ter influenciado a configuração das dimensões no que se refere à importância dada às variáveis de análise. Nesse sentido, a expectativa de um graduando, em geral, é concluir o curso para inserir-se no mercado de trabalho e o salário parece o requisito imediato dessa relação primeira. Após esse estágio, parece coerente que se iniciem outras preocupações, como "arranjei um emprego, e agora?", que denotam a nova relação estabelecida e que deverá ser testada na prática. Assim, o conhecimento aprendido no curso e as competências exigidas na nova função dão contornos para a dimensão complexidade do trabalho.

A terceira fase atua quando as duas primeiras questões não geram mais intensas inquietações, tendo em vista que a equação salário-conhecimento-competências está mais conhecida e organizada na vida do jovem profissional. Nesse sentido, novas questões surgem nesse cenário, como a busca pelo bem-estar, expresso por um novo 
posicionamento no trabalho em busca de um ambiente que desperte sentimentos prazerosos.

Por último, a quarta dimensão configura um trabalhador que possui uma relação de trabalho mais estável e que anseia por manter essa estabilidade, ou progredir em função de uma preocupação com o futuro. Nessa perspectiva, o trabalhador é convocado a rever se o trabalho, atualmente, atende às suas aspirações futuras.

A formação de agrupamentos gerou uma análise complementar, no sentido de verificar a aderência dos fatores por cluster formado. Nesse sentido, percebeu-se que discentes dos cursos de Ciências da Comunicação possuem maior aproximação com a leitura de carreira que emerge do fator 4, com suporte na percepção de que o sucesso se dá em decorrência de um futuro promissor.

Diante desses achados, percebe-se que a discussão sobre carreira pode caminhar no sentido de problematizar essas dimensões e o lugar do aluno, nesses quatro cenários. Pensar carreira dessa forma pode contribuir com processos decisórios importantes, que guiam uma transição delicada na vida de qualquer pessoal. Além do tema carreira ser central na vida do universitário, é um assunto importante para as organizações, repercutindo nas decisões relacionadas à carreira de seus membros, por exemplo, sobre os processos de desenvolvimento, avaliação de desempenho, contratação e demissão (MAGALHÃES, BENDASSOLLI, 2013).

A ampliação da pesquisa, como forma de driblar suas limitações, poderia caminhar no sentido de investigações com uma amostra mais abrangente e diversificada. A estatística escolhida formalizou a existência de uma estrutura quadridimensional, o que pode ser analisado à luz de uma Análise Fatorial Confirmatória. Percebe-se que novos estudos poderiam ampliar os resultados por meio de novos testes estatísticos e/ou por meio de análises com suporte em discursos.

A pesquisa propõe contribuir com a discussão sobre o estudo do sucesso na carreira, numa perspectiva da formação acadêmica. Levantar a estrutura subjacente aos dados e buscar sua coerência teórica, bem como, sua relevância no cenário acadêmico, foi o que instigou a investigação, possibilitando, ainda, o levantamento de questões para discussões futuras. 


\section{REFERÊNCIAS}

ARTHUR, M. B.; KHAPOVA, S. N.; WILDEROM, C. P. M. Career success in a boundaryless career world. Journal of Organizational Behavior, v. 26, p. 177-202, 2005.Disponívelem<http://onlinelibrary.wiley.com/doi/10.1002/job.290/abstract $>$. Acess oem 11 out. 2014.

BARUCH, Y. Developing Career Theory Based on 'New Science': A Futile Exercise? TheDevil's Advocate Commentary, v. 5, n.1, p. 15-21, 2002. Disponível em $<$ http://cairn-int.info/abstract-E_MANA_051_0015--developing-career-theory-basedon.htm>. Acesso em 11 out. 2015.

BASTOS; A. V. B.; YAMAMOTO, O. H.; RODRIGUES, A. C. de A. Compromisso social ético: desafios para a atuação em psicologia organizacional e do trabalho. In: BORGES, L., de O., MOURÃO, L. O trabalho e as organizações: atuações a partir da psicologia. Porto Alegre: Artmed, 2013.

BENDASSOLLI; P. F.; MALVEZZI, S. Desempenho no trabalho: definições, modelos teóricos e desafios à gestão. In: BORGES, L. de O. MOURÃO, L. O trabalho e as organizações: atuações a partir da psicologia. Porto Alegre: Artmed, 2013.

BEZERRA, F.A. Análise Fatorial. In: CORRAR, L. J.; Paulo, E.; DIAS FILHO, J. M. (Orgs.). Análise Multivariada: Para Os Cursos de Administração, Ciências Contábeis E Economia. São Paulo: Atlas, 2009.

BORGES, L., de O., MOURÃO, L. O trabalho e as organizações: atuações a partir da psicologia. Porto Alegre: Artmed, 2013.

BORGES, L. de O.; YAMANOTO, O. H. O mundo do trabalho. In: ZANELLI, J. C.; BORGES-ANDRADE, J. E.; BASTOS, A. V. B. (Org.). Psicologia, organização e trabalho no Brasil.Porto Alegre: Artmed, 2004.

CABRAL et al. Reestruturação e expansão do ensino superior público: o programa Reuni na Universidade Federal do Ceará sob a visão dos alunos. Revista do Serviço Público, v. 62, n. 3, p. 297-319, 2011. Disponível em:

<http://www.enap.gov.br/index.php?option=com_docman\&task=docview\&gid=3717> . Acesso em 30 set. 2014.

CENSO EAD.BR. Organização Associação Brasileira de Educação a Distância. São Paulo: Pearson Education do Brasil, 2010. Disponível em:

http://www.abed.org.br/censoead/CensoEaDbr0809 portugues.pdf. Acesso em 30 set. 2014.

CHANLAT, J., F. Quais carreiras e para qual sociedade? (II). Revista de

Administração de Empresas, São Paulo, v. 36, n. 1, mar. 1996. Disponível em http://www.scielo.br/scielo.php?script=sci arttext\&pid=S003475901996000100003\&lng=pt\&nrm=iso. Acesso em 15 out. 2014.

CLARKE, M. Plodders, pragmatists, visionaries and opportunists: carres patterns an employability theory perspective. British Journal of Management, v. 19, p. 141-149, 2008.Disponívelemhttp://www.emeraldinsight.com/doi/abs/10.1108/136204309109335

Revista Eletrônica Gestão e Serviços v.9, n. 1, pp. 2164-2189, Janeiro/Junho 2018. ISSN Online: 2177-7284 e-mail: regs@ metodista.br 
56.Acesso em 13 out. 2014.

COELHO, J. A. Organizações e Carreiras sem Fronteiras: a Percepção de Formandos sobre a Tendência nas Exigências Profissionais [Dissertação de mestrado em Psicologia]. São Paulo: Universidade de São Paulo, 2000.

COLLIS, Jill; HUSSEY, Roger. Pesquisa em administração: um guia prático para alunos de graduação e pós-graduação, 2. ed. Porto Alegre: Bookman, 2005.

CORNELIUS, N.; SKINNER, D. The careerns of senior men and women: a capabilities theory perspective. British Journal of Management, v. 19, p. 141-149, 2008.Disponívelem <http://papers.ssrn.com/sol3/papers.cfm?abstract id=1095913 > . Acesso em 13 out. 2014.

COSTA, A. R.; VIEIRA, A. M. Percepção de Sucesso na carreira, bem-estar no trabalho e desempenho: Um estudo com professores universitários. Qualit@s Revista Eletrônica. Vol. 16, n. 2, 2014.

COSTA, L. V. A relação entre a percepção de sucesso na carreira e o comprometimento organizacional: um estudo entre professores de universidades privadas selecionadas da grande São Paulo, 216s. Tese (Doutorado em Administração). Universidade de São Paulo, 2010.

COSTA, L. V. Construção e validação de uma escala de percepção de sucesso na carreira. Revista de Carreiras Pessoas - RECAPE, v. 3, n. 1 jan./fev./mar./abr./2013. Disponível em <http://revistas.pucsp.br/index.php/ReCaPe/article/view/15435/11533>. Acesso em 13 out. 2014.

COSTA, L. V. Sucesso na Carreira. In: SIQUEIRA, M. M. M. et al. Medidas do comportamento organizacional: ferramentas de diagnóstico e de gestão. Porto Alegre: Artmed, 2014.

DRIES, N.; PEPERMANS, R.; CARLIER O. Career success: Constructing a multidimensional model. Journal of Vocational Behavior, v. 73, p. 254-267, 2008. Disponível em <http://www.sciencedirect.com/science/article/pii/S000187910800047X > Acesso em 11 out. 2014.

DUARTE, M. de F.; SILVA, A. L. A reconstrução da carreira em ambientes de trabalho em transformação.Organização \& Sociedade, Salvador, v. 20,n. 67, dez. 2013. Disponível em <http://www.scielo.br/scielo.php?script=sci arttext\&pid=S198492302013000400009\&lng=pt\&nrm=iso>.Acesso em 16 out. 2014.

DUTRA, J. S.; VELOSO, E. F. R.;FISCHER, A. L.; NAKATA, L. E. As carreiras inteligentes e sua percepção pelo clima organizacional. Revista Brasileira de Orientação Profissional, v. 10, n. 1, p. 55-70, 2009. Disponível em<http://pepsic.bvsalud.org/pdf/rbop/v10n1/v10n1a08.pdf>. Acesso em: 11 out. 2014. FISCHER, M.; GRECA, A.; GOMES, C.; MOSER, A. Percepção de Carreira e Projeto Profissional de alunos do curso de Biologia. Estudos biológicos, 2012, jan./abr.; 34 (82): p. 9-21, 2012. 
HAIR, F.J.; BLACK, W. C.; BABIN, B.; ANDERSON, R. E.; TATHAN, R. L. Análise multivariada de dados,6. ed. Porto Alegre: Bookman, 2009.

HALL, D. T. Careers in and out of organization. Thousand Oaks CA: Sage Publications,2002. Disponível em: http://books.google.com.br/books?id=kzaiMJbrWEC\&pg=PA3\&hl=pt$\underline{B R \& \text { source }=g b s \_ \text {toc } r \& c a d=4 \# \mathrm{v}=\text { onepage } \& q \& \mathrm{f}=\text { false. }}$. Acesso em 11 out. 2014.

JUDGE, T. A., CABLE, D. M., BOUDREAU, J. W., \& BRETZ, R. D.An empiricalinvestigation of the predictors of executive career success.Personnel Psychology, v.48, n. 3,p. 485-

519,1995.Disponívelemhttp://digitalcommons.ilr.cornell.edu/cgi/viewcontent.cgi?article $=1232 \&$ context=cahrswp. Acesso em 11 out. 2014.

KOEN, J., KHLEHE, U., VAN VIANEN, A. E. M. Training career adaptability to facilitate a successful school-to-work transition. Journal of Vocational Behavior, 81, 395-408, 2012.Disponívelem: $<$ http://www.sciencedirect.com/science/article/pii/S0001879112001 $\underline{39 X}>$. Acesso em 15 out. 2014.

LEMOS, C.; G. de et al. Referenciais de carreira e identidade profissional em estudantes universitários.Psicologia Ciência e Profissão. Brasília, v. 27, n. 2, jun. 2007. Disponível em http://www.scielo.br/scielo.php?script=sci_arttext\&pid=S141498932007000200004\&lng=pt\&nrm=iso. Acesso em 16 out. 2014.

LIMA, T. C. B.; ARRAES, A. P.; PAIVA, V. M.; BRANDÃO, L. E. A Percepção de Sucesso na Carreira do Docente de Educação Profissional no Setor Industrial. X Congresso Nacional e Excelência em Gestão (Gestão e Design de Produtos e Serviços para a Sustentabilidade). Rio de Janeiro, Niterói, 8 e 9 de agosto de 2014.

MAGALHÃES, M.; de O.; BENDASSOLLI, P., F. Desenvolvimento de carreira nas organizações. In: BORGES, L., de O., MOURÃO, L. O trabalho e as organizações: atuações a partir da psicologia. Porto Alegre: Artmed, 2013.

MAGALHAES, M., de O.; TEIXEIRA, M., A., P. Antecedentes de comportamentos de busca de emprego na transição da universidade para o mercado de trabalho. Psicologia: Teoria e Pesquisa, Brasília, v. 29, n. 4, dez. 2013. Disponível em:http://www.scielo.br/scielo.php?script=sci_arttext\&pid=S0102$\underline{37722013000400007 \& \operatorname{lng}=\text { pt\&nrm=iso. }}$. Acesso em 16 out. 2014.

MALHOTRA, N. K. Pesquisa de marketing: uma orientação aplicada,6. ed. Porto Alegre: Bookman, 2012.

MOTA, P. R. Reflexões sobre a customização das carreiras gerenciais: a individualidade e a competitividade contemporâneas. In: BALASSIANO, M; COSTA, I. de S. A. da (Org.) Gestão de Carreiras: dilemas e perspectivas. São Paulo: Atlas, 2006.

PERRONE, L., VICKERS, M. H. Life after graduation as a "very uncomfortable world": An australian case study. Education and Training, 45(2/3), 69-78, 2003.Disponívelem: $<$ http://homepages.se.edu/cvonbergen/files/2013/01/Life-afterGraduation-As-A-Very-Uncom fortable-World_An-Australian-Case-Study.pdf > 
Acesso em 12 out. 2014.

RICHARDSON, R. Pesquisa social: métodos e técnicas, 3. ed. São Paulo, Atlas, 1999.

ROCHA, J., B., da; KUBO, E. K. de M.; LEITE, N. R. P.; OLIVA, E. de, C.; FARINA, M. C. Percepção de Sucesso na Carreira da Mulher Executiva Brasileira. XXXVII Encontro da ANPAD, 2013.

ROCHA. J., B.Percepção de sucesso na carreira na mulher executiva brasileira. Dissertação de Mestrado em Administração.Universidade Municipal de São Caetano do Sul, 2013. Disponível em

<http://www.uscs.edu.br/posstricto/administracao/dissertacoes/2013/pdf/dissertacao me strado_Jane_B_Rocha_Fev2013.pdf> Acesso em 14 out. 2014.

SILVA, C. S. C. De estudante a profissional: a transição de papéis na passagem da universidade ao mercado de trabalho[Dissertação de mestrado em Psicologia]. Universidade Federal do Rio Grande do Sul, Porto Alegre, RS, 2010. Disponível em $<$ http://www.lume.ufrgs.br/handle/10183/25809?locale=pt_BR $>$. Acesso em 13 out. 2014.

SILVA, C.S.C. da; TEIXEIRA, M., A., P. Experiências de Estágio: Contribuições para a Transição Universidade-Trabalho. Paidéia (Ribeirão Preto), Ribeirão Preto, v. 23, n. 54, abr. 2013. Disponível em <http://www.scielo.br/scielo.php?script=sci_arttext\&pid=S0103-

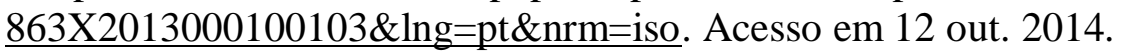

SIQUEIRA, M. M. Novas Medidas do Comportamento Organizacional: ferramentas de diagnóstico e de gestão. Porto Alegre: Artmed, 2014.

SOUZA, E. C. L. de; DEPIERI, C. C. L. de S.; ASSIS, S. de A. G.; ZERBINI, T. Métodos, técnicas e recursos didáticos de ensino do empreendedorismo em IES brasileiras. In: E. C. L. de SOUZA; T. de A. GUIMARÃES (Orgs.).

Empreendedorismo além do plano de negócio. São Paulo: Atlas, p. 200-216, 2006.

STEVENSON, W. J. Estatística aplicada à Administração. São Paulo: Harper \&Row do Brasil, 2001. STURGES; GUEST, 2004.

STURGES, J. All in a day's work?Career self-management and the management of the boundary between work and non-work.Human Resource Management Journal, v. 18, n. 2, p. 118-134, 2008.

STURGES, J.; GUEST, D. Working to live or living to work?Work/life balance early in the career.Human Resource Management Journal, v. 14, n. 4, p. 5-20, 2004.

TEIXEIRA, M., A., P.; GOMES, W., B. Decisão de carreira entre estudantes em fim de curso universitário.Psicologia: Teoria e Pesquisa, Brasília, v. 21, n. 3, dez. 2005.

Disponível em http://www.scielo.br/scielo.php?script=sci arttext\&pid=S010237722005000300009\&lng=pt\&nrm=iso. Acesso em: 10 out. 2014. 